\title{
Pulmonary function and quality of life after aortic valve replacement through ministernotomy: a prospective randomized study
}

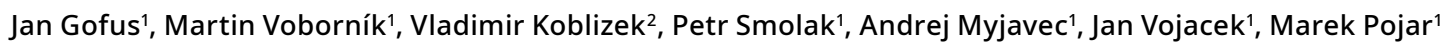

1 Department of Cardiac Surgery, Charles University, Faculty of Medicine and University Hospital in Hradec Kralove, Hradec Kralove, Czech Republic

2 Department of Pulmology, Charles University, Faculty of Medicine and University Hospital in Hradec Kralove, Hradec Kralove, Czech Republic

Correspondence to: Martin Voborník, MD, PhD, Department of Cardiac Surgery, University Hospital in Hradec Kralové, Sokolská 581, 50005 Hradec Králové, Czech Republic, phone: +420495832422, email: martinvobornik@seznam.cz, Received: June 6, 2020. Revision accepted: October 19, 2020. Published online: October 27, 2020. Kardiol Pol. 2020; 78 (12): $1278-1280$ doi:10.33963/KP.15668 Copyright by the Author(s), 2020
Introduction In the era of mini-invasive procedures and a widespread use of transcatheter approaches, growing attention has been focused on mini-invasive cardiac surgery. Ministernotomy (or upper partial sternotomy, or upper hemisternotomy [UHS]) ${ }^{1}$ is currently the most popular mini-invasive surgical approach to aortic valve replacement worldwide. ${ }^{2,3}$ While it preserves a comparable mortality rate, this approach has been associated with reduced perioperative morbidity and faster rehabilitation nonetheless. ${ }^{4-7}$ Preserving the lower half of thoracic cage could lead to better postoperative pulmonary function. However, the available literature on this topic is controversial. ${ }^{8-10}$ Heath-related quality of life (HRQoL) after mini-invasive aortic valve replacement has not been fully evaluated.

The aim of our study was to compare UHS with standard full median sternotomy (FS) in terms of pulmonary function and HRQoL.

Methods We prospectively included patients referred for isolated biological aortic valve replacement. The patients were 65 years of age or older and fully eligible for both surgical approaches based on standard chest X-ray and aortography. The exclusion criteria were re-do surgery and concomitant cardiac surgery. The study was approved by the local ethics committee and all patients provided their informed consent. Using a random number generator, patients were randomized in a 1-to-1 ratio to either the UHS or FS group.

On the day prior to surgery $\left(D_{0}\right)$, the patients underwent a complete pulmonary function testing (PFT) and filled the 36-Item Short Form
Health Survey (SF-36). The PFT (involving spirometry, body plethysmography, and transfer factor assessment) were performed according to the American Thoracic Society/ European Respiratory Society guidelines. ${ }^{11}$ The surgery was performed the next day in either a mini-invasive or standard manner. The FS group was operated in a standard fashion. The UHS group was operated through a "J" shape splitting of the sternum from the jugular notch to the level of third or fourth intercostal space with central cannulation of the ascending aorta and the superior vena cava. A stented bioprosthesis (Crown PRT, LivaNova, London, United Kingdom) was implanted in all of the patients in a supra-annular fashion using double-pledgeted interrupted stitches. The sternum was closed with horizontal steel wires. On the postoperative day $7\left(D_{7}\right)$ we repeated the PFT and the patient was discharged. A control evaluation was performed at our outpatient department 3 months after surgery $\left(D_{90}\right)$, which included both a PFT and the SF-36.

Statistical analysis All calculations were conducted using the NCSS 11 statistical software (2016, Kaysville, Utah, United States). Categorical variables are expressed as numbers and percentages. Continuous data are expressed as medians and interquartile ranges. All comparisons in brackets are presented as UHS versus FS group. Quantitative variables were tested with a 2-sample $t$ test for variables with parametric distribution and the Mann-Whitney test or the Kolmogorov-Smirnov test for variables with nonparametric data distribution. Categorical data were evaluated with the $\mathrm{X}^{2}$ test or the Fisher 

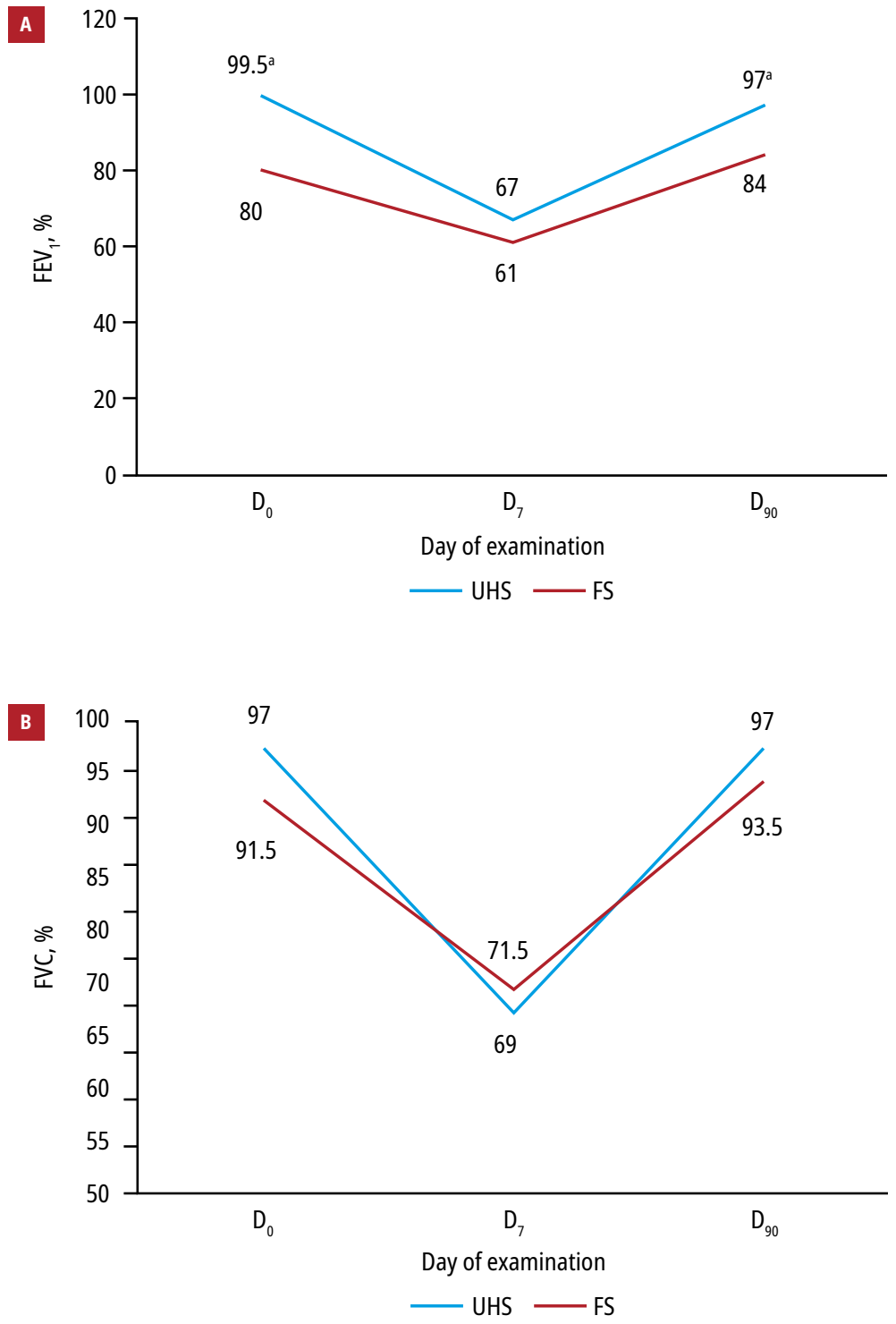

FIGURE 1 Perioperative dynamics of pulmonary function: A - forced expiratory volume in the first second $\left(\mathrm{FEV}_{1}\right)$; $\mathbf{B}$ - forced vital capacity $(\mathrm{FVC})$; both expressed relative to the predicted value (\%)

a $P$ value $<0.05$

Abbreviations: $\mathrm{D}_{0}$, preoperative measurement; $\mathrm{D}_{7}$, measurement on postoperative day 7 ;

$\mathrm{D}_{90}$, measurement after 3 months; FS, full sternotomy; UHS, upper hemisternotomy

exact tests. The repeated measures analysis of variance with a post-hoc Fisher least significant difference test was used to compare the pulmonary function and HRQoL outcomes between the groups. To further evaluate these parameters, we used actual and relative differences between the obtained values. Patients were evaluated according to the intention-to-treat principle. A $P$ value of less than 0.05 was considered statistically significant for all tests.

Results and discussion A total of 40 patients were included to the study between May 2017 and September 2019. Twenty of them were operated by UHS and 20 by FS. Patients in the UHS group had a lower body weight (76 kg vs $91 \mathrm{~kg}$; $P=0.02)$. There was no in-hospital mortality.
The UHS group had a longer operation time (175 minutes vs 160 minutes; $P=0.02$ ). Both groups had comparable artificial ventilation time (10 hours vs 8.8 hours; $P=0.77$ ), length of stay at the intensive care unit (24 hours vs 21.1 hours; $P=0.17$ ), and length of stay at the hospital (9 days vs 9 days; $P=0.23$ ). The UHS group had significantly lower blood loss postoperatively $(250 \mathrm{ml}$ vs $400 \mathrm{ml} ; P<0.001)$. We recorded 2 conversions from UHS to FS (10\%): one due to anatomic considerations and the other due to a surgical complication. No other perioperative differences were observed (Supplementary material, Table S1).

Although the forced expiratory volume in the first second was preoperatively higher in the UHS group (99.5\% vs $80 \%$; $P=0.002$ ), this difference disappeared on the $\mathrm{D}_{7}(67 \%$ vs $61 \%$; $P=0.4)$. Actual difference between these 2 measurements was higher in the UHS group $(-34 \%$ vs $-17 \% ; P=0.003)$. The values returned to normal after three months ( $97 \%$ vs $84 \% ; P=0.008$ ). A similar trend was seen in the maximal expiratory flow at $50 \%$ of vital flow capacity.

The parameters of restriction were preoperatively comparable. However, the UHS group showed a significantly more pronounced drop in vital capacity $(-32.5 \%$ vs $-22.5 \% ; P=0.03)$ and forced vital capacity ( -31 vs $-20.5 \% ; P=0.03$ ) on $\mathrm{D}_{7}$ measurement. These values returned to preoperative levels after 3 months (FIGURE 1). No other differences were found in other parameters of obstruction, restriction, pulmonary hyperinflation or diffusion.

Regarding the HRQoL, UHS patients displayed a greater improvement in physical function after the surgery (30 points vs 2.5 points; $P=0.03$ ). Further, UHS patients showed greater improvement in general health status according to the analysis of variance when compared with FS patients $(P=0.049)$. No differences were observed in the remaining categories (Supplementary material, Table S2).

Our study showed that UHS results in a significantly lower postoperative blood loss in comparison with FS, which is consistent with other studies. ${ }^{4,8,12,13}$ However, this was not reflected by a lower requirement for blood transfusion, as previously reported by Lim et $\mathrm{al}^{6}$ and Hancock et al. ${ }^{13}$

Mini-invasive approach could be associated with shorter ventilation times as well as with shorter hospital and intensive care unit length of stay. ${ }^{4-6,12}$ However, this was not confirmed in our study.

The benefits of mini-invasive approaches are associated with increased technical demand of the procedure. This is reflected by longer operation times in our study, as well as in most of the above-mentioned papers. The issue could be addressed in the future by implementing sutureless aortic valve prostheses. Improvements in 
procedure time have been demonstrated, together with good short- and mid-term outcomes. ${ }^{14,15}$

The data on PFT after ministernotomy are controversial. Calderon et $\mathrm{al}^{8}$ did not find any differences between the UHS and FS groups, whereas that Bonacchi et $\mathrm{al}^{9}$ and Candaele et a $1^{10}$ reported an improved outcome for ministernotomy patients. In contrast, our study showed that, despite better preoperative values, the UHS group displayed a more pronounced drop in some of the parameters when compared with the FS. However, most of them returned to normal after 3 months.

Regarding the study limitations, the low number of patients is the most important issue. In addition, the difference in preoperative pulmonary function between the groups could induce a bias in the postoperative dynamics.

To conclude, the UHS approach is associated with lower postoperative blood loss. It provides a greater short-term HRQoL improvement, but does not lead to better pulmonary function postoperatively.

\section{SUPPLEMENTARY MATERIAL}

Supplementary material is available at www.mp.pl/kardiologiapolska.

\section{ARTICLE INFORMATION}

ACKNOWLEDGMENTS The authors thank Dr. Eva Cermakova for conducting all statistical analyses. The work was supported by the program Progres Q40/04 and SWV 260545, Charles University, Prague. The authors thank Daniel Díaz, PhD, for his assistance in editing and proofreading of this manuscript.

CONFLICT OF INTEREST None declared.

OPEN ACCESS This is an Open Access article distributed under the terms of the Creative Commons Attribution-NonCommercial-NoDerivatives 4.0 International License (CC BY-NC-ND 4.0), allowing third parties to download articles and share them with others, provided the original work is properly cited not changed in any way, distributed under the same license, and used for noncommercial purposes only. For commercial use, please contact the journal office at kardiologiapolska@ptkardio.pl.

HOW TO CITE Gofus], VobornikM, KoblizekV, et al. Pulmonary function and quality of life after aortic valve replacement through ministernotomy: a prospective randomized study. Kardiol Pol. 2020; 78: 1278-1280. doi:10.33963/KP.15668

\section{REFERENCES}

1 Svensson LG. Minimal-access "J" or "j" sternotomy for valvular, aortic, and coronary operations or reoperations. Ann Thorac Surg. 1997; 64: 1501-1503.

2 Kaneko T, Vassileva CM, Englum B, et al. Contemporary outcomes of repeat aortic valve replacement: a benchmark for transcatheter valve-in-valve procedures. Ann Thorac Surg. 2015; 100: 1298-1304.

3 Young $C P$, Sinha S, Vohra HA. Outcomes of minimally invasive aortic valve replacement surgery. Eur J Cardiothorac Surg. 2018; 53: 19-23.

4 Kirmani BH, Jones SG, Malaisrie SC, et al. Limited versus full sternotomy for aortic valve replacement. Cochrane Database Syst Rev. 2017; 4: CD011793.

5 Phan K, Xie A, Tsai Y-C, et al. Ministernotomy or minithoracotomy for minimally invasive aortic valve replacement: a Bayesian network meta-analysis. Ann Cardiothorac Surg. 2014; 4: 3-14.

$6 \operatorname{Lim}$ JY, Deo SV, Altarabsheh SE, et al. Conventional versus minimally invasive aortic valve replacement: pooled analysis of propensity-matched data. J Card Surg. 2015; 30: 125-134.

7 Chang C, Raza S, Altarabsheh SE, et al. Minimally Invasive approaches to surgical aortic valve replacement: a meta-analysis. Ann Thorac Surg. 2018; 106: 1881-1889.

8 Calderon J, Richebe P, Guibaud JP, et al. Prospective randomized study of early pulmonary evaluation of patients scheduled for aortic valve surgery performed by ministernotomy or total median sternotomy. J Cardiothorac Vasc Anesth. 2009; 23: 795-801.

9 Bonacchi M, Prifti E, Giunti G, et al. Does ministernotomy improve postoperative outcome in aortic valve operation? A prospective randomized study. Ann Thorac Surg. 2002; 73: 460-465.
10 Candaele S, Herijgers P, Demeyere R, et al. Chest pain after partial upper versus complete sternotomy for aortic valve surgery. Acta Cardiol. 2003; 58: 17-21.

11 Miller MR, Crapo R, Hankinson J, et al. General considerations for lung function testing. Eur Respir J. 2005; 26: 153-161.

12 Khoshbin E, Prayaga S, Kinsella J, Sutherland FW. Mini-sternotomy for aortic valve replacement reduces the length of stay in the cardiac intensive care unit: meta-analysis of randomised controlled trials. BMJ Open. 2011; 1: e000266.

13 Hancock HC, Maier RH, Kasim AS, et al. Mini-sternotomy versus conventional sternotomy for aortic valve replacement. J Am Coll Cardiol. 2019; 73: 2491-2492.

14 Meco M, Montisci A, Miceli A, et al. Sutureless perceval aortic valve versus conventional stented bioprostheses: meta-analysis of postoperative and midterm results in isolated aortic valve replacement. J Am Heart Assoc. 2018; 7: e006091.

15 Filip G, Litwinowicz R, Kapelak B, et al. Mid-term follow-up after suture-less aortic heart valve implantation. J Thorac Dis. 2018; 10: 6128-6136. 